\title{
Prevalence of Non-Tuberculous Mycobacteria in Hospital Waters of Major Cities of Khuzestan Province, Iran
}

\author{
Azar Dokht Khosravi 1,2, Abdolrazagh Hashemi Shahraki ${ }^{1,3}$, Mohammad Hashemzadeh 2, 4*, \\ Rasa Sheini Mehrabzadeh ${ }^{1}$ and Ali Teimoori ${ }^{5}$ \\ ${ }^{1}$ Health Research Institute, Infectious and Tropical Diseases Research Center, Ahvaz Jundishapur University of Medical \\ Sciences, Ahvaz, Iran, ${ }^{2}$ Department of Microbiology, School of Medicine, Ahvaz Jundishapur University of Medical Sciences, \\ Ahvaz, Iran, ${ }^{3}$ Department of Epidemiology, Pasteur Institute of Iran, Tehran, Iran, ${ }^{4}$ Student Research Committee, Ahvaz \\ Jundishapur University of Medical Sciences, Ahvaz, Iran, ${ }^{5}$ Department of Virology, School of Medicine, Ahvaz Jundishapur \\ University of Medical Science, Ahvaz, Iran
}

\section{OPEN ACCESS}

Edited by:

Thomas A. Ficht,

Texas A\&M University, USA

Reviewed by:

William D. Picking

University of Kansas, USA

Marina Santic',

University Of Rijeka, Croatia

${ }^{*}$ Correspondence:

Mohammad Hashemzadeh

hashemzademh@gmail.com

Received: 21 January 2016

Accepted: 26 March 2016

Published: 13 April 2016

Citation:

Khosravi AD, Hashemi Shahraki A,

Hashemzadeh M, Sheini

Mehrabzadeh R and Teimoori A (2016)

Prevalence of Non-Tuberculous

Mycobacteria in Hospital Waters of

Major Cities of Khuzestan Province,

Front. Cell. Infect. Microbiol. 6:42. doi: 10.3389/fcimb.2016.00042
Non-tuberculous mycobacteria (NTM) are among the emerging pathogens in immunocompromised individuals including hospitalized patients. So, it is important to consider hospitals water supplies as a source for infection. The aim of this study was to determine the prevalence of NTM in the hospital aquatic systems of Khuzestan, South west of Iran. In total, 258 hospital water samples were collected and examined. After initial sample processing, sediment of each sample were inoculated into two Lowenstein-Jensen medium. The positive cultures were studied with phenotypic tests including growth rate, colony morphology, and pigmentation, with subsequent PCR- restriction enzyme analysis (PRA) and rpoB gene sequence analysis. Mycobacterial strains were isolated from 77 samples (29.8\%), comprising $52(70.1 \%)$ rapid growing, and 25 (32.4\%) slow growing mycobacteria. Based on the overall results, M. fortuitum (44.1\%) was the most common mycobacterial species in hospital water samples, followed by $M$. gordonae $(n=13,16.8 \%)$ and $M$. senegalense $(n=5,7.7 \%)$. In conclusion, current study demonstrated the NTM strains as one of the major parts of hospital water supplies with probable potential source for nosocomial infections. This finding also help to shed light on to the dynamics of the distribution and diversity of NTM in the water system of hospitals in the region of study.

Keywords: non-tuberculous mycobacteria, polymerase chain reaction, restriction enzyme analysis, water samples

\section{INTRODUCTION}

Non-tuberculous mycobacteria (NTM) are widely present in the environment and are commonly isolated from environmental sources including water (Decker and Palmore, 2013). Several species of environmental mycobacteria have been known to be important human pathogens, and reports suggest that there is an increasing trend in the incidence of NTM disease (Moore et al., 2010; Donohue et al., 2015), and in particular, in immunocompromised patients (Parashar et al., 2004; Narang et al., 2009). In a recently published meta-analysis, high prevalence of NTM infections (10.2\%) was reported among culture-positive cases of tuberculosis (TB) in Iran, which emphasizes on the role of NTM in human public health (Nasiri et al., 2015). Exposure to NTMs occurs primarily 
through human interactions with water (Donohue et al., 2015). In particular, NTM species can multiply in the numerous water sources, including waste water, surface water, ground water, and tap water (Edirisinghe et al., 2014). Mycobacteria are able to multiply within low nutrient environment particularly water pip systems and can survive in hospital hot water systems, and resist chlorination. Moreover, biofilm formation, amoeba-associated lifestyle, and resistance to chlorine have been recognized as important factors that contribute to the survival, colonization and persistence of NTM in water distribution systems (Vaerewijck et al., 2005; Castillo-Rodal et al., 2012; Falkinham, 2015; Iii, 2015). The incidence of NTM has been reported different from one setting to another, ranging from 40 (Shin et al., 2007) to 58\% (Crago et al., 2014). Some aquatic systems such as hospital water lines are more suitable for colonization with mycobacteria and biofilm formation (Decker and Palmore, 2013). NTM are among the cause of opportunistic nosocomial infections in different clinical settings both in developed and developing countries, but there is little known about the isolation and identification of NTM in Iranian hospitals. So, the aim of this study was to determine the prevalence of NTM in the hospital aquatic systems of Khuzestan, Southwest of Iran, as the first survey on epidemiologic status and distribution of NTM species in hospital waters in the region of study.

\section{MATERIALS AND METHODS}

\section{Sample Collection}

In total, 258 water samples were collected from different sites of teaching hospitals in the major cities of Khuzestan province (Ahvaz, Dezful and Abadan), from 2013 to 2015. These included tap water, dentistry unit water, haemodialysis center fluid, ventilator water, and drinking water tanks. Approximately one liter of each sample was collected in a sterile glass bottle, transferred to laboratory in an icebox and analyzed within 24 hrs. Chlorinated drinking water was the source of water tanks and dentistry unit water system, while sterile water used as water source of ventilator systems. Stranded procedure used to produce water for hemodialysis machines (CDC, 2003).

\section{Sample Preparation and Culture}

The samples were processed and decontaminated as previously described (Peters et al., 1995). In brief, $500 \mathrm{ml}$ of each water sample was filtered through a membrane filter (pore size $0.45 \mu \mathrm{m}$; Millipore, Bedford, U.S.A), and was decontaminated by $0.005 \%$ cetylpyridinium chloride for $30 \mathrm{~min}$ at room temperature. Two hundred $\mu \mathrm{l}$ of sediments were inoculated into two LowensteinJensen (LJ) media (HiMedia, India), and incubated at 37 and $25^{\circ} \mathrm{C}$ for 2 months. The cultures were observed twice per week for growth rate, colony morphology, and pigmentation. Colonies were stained by the Ziehl-Neelsen method for the presence of acid fast bacilli (AFB). For acid fast positive colonies, standard phenotypic tests including niacin accumulation, nitrate reduction, catalase activity, iron uptake, and arylsulfatase activity were performed according to the standard instructional
(Kent and Kubica, 1985), followed by molecular identification technique.

\section{Molecular Identification DNA Extraction}

Genomic DNA was extracted from colonies using lipase (Type VII; final concentration, $2 \mathrm{mg} / \mathrm{ml}$ [Sigma]), proteinase $\mathrm{K}$ $(100 \mathrm{pg} / \mathrm{ml})$ and $0.5 \%$ sodium dodecyl sulfate treatment as described by Neumann et al. (1997). The DNA was purified by phenol chloroform isoamyl alcohol and precipitated with isopropanol. The precipitate was washed in 70\% ethanol, dehydrated and dissolved in $100 \mu \mathrm{l}$ of Milli-Q water and stored in $20^{\circ} \mathrm{C}$ until use.

\section{PCR Restriction Enzyme Analysis (PRA)-Based Identification Method}

An approximately $441 \mathrm{bp}$ fragment of the $h s p 65$ gene was amplified by PCR using two specific primers Tb11 (5'ACCAACGATGGTGTGTCCAT-3') and Tb12 (5'-CTTGTC GAACCGCA- TACCCT- $3^{\prime}$ ). Genomic DNA of M. fortuitum ATCC 49404T and double distilled water were used as positive and negative controls, respectively. PCR products of $h s p 65$ gene were digested by the BstEII and HaeIII restriction enzyme according to previously described protocol (Telenti et al., 1993). The fragments were compared with those of patterns deposited in a free available database (http://app.chuv.ch/prasite, n.d.), for species identification.

\section{Sequencing of rpoB Gene}

A 750-bp fragment of the $r p o B$ gene was amplified using primers MycoF (5'- GGCAAGGTCACCCCGAAGGG-3') and MycoR (5'-AGCGGCTGCTGGGTGATCATC- $3^{\prime}$ ) with instruction described by Adékambi et al. (2003). The cycling condition was $95^{\circ} \mathrm{C}$ for $1 \mathrm{~min}$, followed by 30 cycles of $95^{\circ} \mathrm{C}$ for $30 \mathrm{~s}, 64^{\circ} \mathrm{C}$ for $30 \mathrm{~s}$, and $72^{\circ} \mathrm{C}$ for $30 \mathrm{~s}$ and finalized with $72^{\circ} \mathrm{C}$ for $5 \mathrm{~min}$.

\section{Sequence Data and Phylogenetic Analysis}

The sequences of $r p o B$ gene for each isolate were aligned separately and compared with all existing relevant sequences of mycobacteria recovered from GenBank database using JPhydit program (Jeon et al., 2005). Percentages of similarity between sequences of each gene were determined by comparing sequences to an in-house database of $r p o B$ sequences. Phylogenetic trees were obtained from DNA sequences using the Neighbor-Joining (N) method and Kimura's two parameter (K2P) distance correction model with 1000 bootstrap replications supported by the MEGA 6 software (Tamura et al., 2007).

\section{Nucleotide Sequence Accession Numbers}

The GenBank accession numbers of investigated isolates of NTM determined in this work are KU198411-KU198415, KU240541KU240549, and KU212280 for rpoB gene.

\section{Statistical Analysis}

Data was shown through the simple predictive statistics, prevalence value and no any statistical method was used for comparing and prediction. Our proposed goal was completed with distribution and prevalence value of NTM in each location. 
TABLE 1 | Distribution of water samples from hospitals in different cities of Khuzestan, Iran.

\begin{tabular}{lcccc}
\hline \multirow{2}{*}{ Location } & \multicolumn{3}{c}{ Water samples $(\boldsymbol{n}=\mathbf{1 0 5})$} & Total \\
\cline { 2 - 4 } & Positive & Negative & Contaminated & \\
\hline Ahvaz & $47(26.1 \%)$ & $115(63.8 \%)$ & $18(10 \%)$ & $180(40 \%)$ \\
Abadan & $17(42.5 \%)$ & $22(55 \%)$ & $1(2.5 \%)$ & $40(12.3 \%)$ \\
Dezful & $13(34.2 \%)$ & $23(60.5 \%)$ & $2(5.2 \%)$ & $38(13.3 \%)$ \\
\hline
\end{tabular}

\section{RESULTS}

The analyzed water samples comprised: 180 from Ahvaz, 40 from Abadan, and 38 from Dezful. AFB isolated from 77 (29.8\%) samples. One hundred and sixty (62\%) samples were smear and culture negative and the remaining samples 21 (8.1\%), were contaminated (Table 1). According to phenotypic tests, from 77 NTM species, $52(70.1 \%)$ strains of rapid growing mycobacteria (RGM), and 25 (32.4\%) strains of slowly growing mycobacteria (SGM) were detected. Table 1 represents the detailed distribution of water samples from hospitals in three cities of Khuzestan province. M. fortuitum complex-like group was the most frequently encountered species $(n=40,51.9 \%)$, followed by $M$. gordonae-like organisms $(n=13,16.8 \%)$ and Mycobacterium avium complex $(n=5,6.4 \%)$. The remaining isolates were unidentifiable with phenotypic evaluation $(n=$ $16,20.7 \%)$. By using hsp65-PRA, M. fortuitum was the most frequently encountered species $(n=34,44.1 \%)$, followed by M. gordonae, $(n=13,16.8 \%)$. The remaining 30 isolates, were mostly showed identical PRA pattern with other species or unique and unknown patterns in comparison to patterns deposited in free available database (http://app.chuv.ch/prasite). For more precise identification and reliable access to species spectrum of the NTM isolates, randomly selected isolates from each cluster of hsp65-PRA, were subjected to sequence based identification using $r p o B$ gene. NTM isolates from all clusters except two (SD31 and SD51), were confidently identified by $r p o B$ gene. The latter two strains were clearly differed from any other known Mycobacterium species and displayed the best resemblance with $M$. arupense and M. wolinsky, respectively. The results of NTM identification by phenotypic tests, PRA and sequence analysis are presented in details in Table 2. Several clusters were characterized in RGM and SGM groups by phylogenetic constructed tree using $r p o B$ gene. The isolates SD31 and SD51 characterized with separated clusters with high bootstrap percentages, representing distinct species (Figure 1). The frequency of NTM species in different hospital water sources and geographic distribution of these species among the hospitals of three cities of Khuzestan, are presented in Table 3; Figure 2, respectively.

\section{DISCUSSION}

In present study, we applied a combination of phenotypic and molecular methods for the detection and identification of NTM species in hospital water samples. Totally, AFB were isolated
TABLE 2 | Results of NTM identification by phenotypic and molecular tests using combination of phenotypic and molecular methods.

\begin{tabular}{|c|c|c|c|}
\hline \multirow{2}{*}{$\begin{array}{l}\text { Number of } \\
\text { isolates }\end{array}$} & \multicolumn{3}{|c|}{ Identification by } \\
\hline & Phenotypic tests & PRA & $\begin{array}{l}\text { rpoB gene } \\
\text { sequence }\end{array}$ \\
\hline 34 & M. fortuitum complex & M. fortuitum & M. fortuitum \\
\hline 13 & M. gordonae like & M. gordonae group & M. gordonae \\
\hline 4 & Mycobacterium sp & $\begin{array}{l}\text { M. phocaicum or } \\
\text { M. mucogenicum }\end{array}$ & M. phocaicum \\
\hline 6 & M. fortuitum complex & $\begin{array}{l}\text { M. conceptionense } \\
\text { or } M . \text { senegalense }\end{array}$ & M. senegalense \\
\hline 3 & M. simiae like & $\begin{array}{l}\text { M. lentiflavum/M. } \\
\text { simiae }\end{array}$ & M. simiae \\
\hline 5 & M. avium complex & $\begin{array}{l}\text { M. colombiense/M. } \\
\text { avium subsp. avium }\end{array}$ & M. colombiense \\
\hline 4 & Mycobacterium sp & M. lentiflavum & M. lentiflavum \\
\hline 3 & Mycobacterium sp & M. novocastrense & M. novocastrense \\
\hline 2 & Mycobacterium sp & unknown & M. engbaekii \\
\hline 1 & Mycobacterium sp & unknown & M. iranicum \\
\hline 1 & Mycobacterium sp & M. arupense & Unidentified \\
\hline 1 & Mycobacterium sp & unknown & Unidentified \\
\hline
\end{tabular}

PRA, PCR restriction enzyme analysis.

from 77 (29.8\%) samples, of which, 52 (70.1\%) were RGM, and 25 (32.4\%) strains were SGM. Our recovery percentage is lower than other investigations on hospital waters (Shin et al., 2007, 2008; Hussein et al., 2009; Fernandez-Rendon et al., 2012). This may be explained by the lower number of examined samples by them compared to our study. Our findings confirmed that species identification by $h s p 65$-PRA was significantly more accurate than the phenotypic methods, as other investigators reported (Martin et al., 2007; Chimara et al., 2008). The limitations associated with phenotypic tests and PRA, such as the presence of unknown patterns, and species with identical patterns, highlights the need for more reliable identification methods (Moghim et al., 2012). Sequence based methods offer much more resolution in identification of NTM compared to other assays (Adékambi et al., 2003). Based on the rpoB gene sequences analysis, 75 (97.4\%) isolates were identified correctly to the species level.

In current study, $M$. fortuitum and $M$. gordonae were the most common inhabitant species recovered from hospital water samples. Recovery of these two species clearly demonstrated that these are the core of culturable microbial community living at different water distribution systems. However, the occurrence of each NTM species at different points of hospital water distribution systems, remained to be investigated in future studies. In one hand, two species of $M$. fortuitum and $M$. gordonae were the most frequently recovered species from all three parts of Khuzestan province (Figure 2), indicating that there was a distinct and identical distribution pattern among the hospital water samples. on the other hand, two reports from this part of Iran, showed that $M$. fortuitum was the dominant potential pathogen recovered from clinical samples (Khosravi et al., 2009; Hashemi-Shahraki et al., 2013), highlights the role of water as bridge between environment and disease caused 


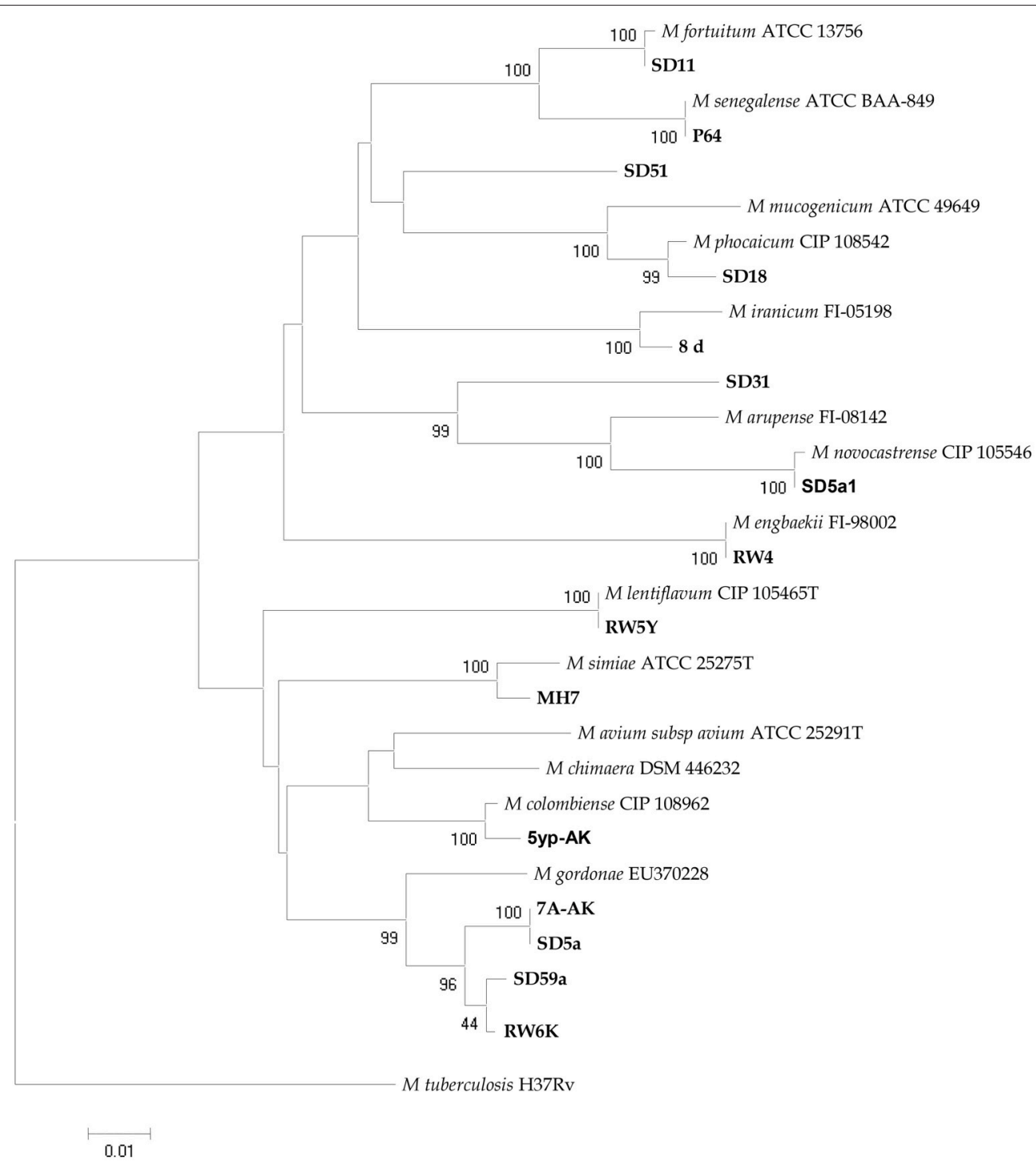

FIGURE 1 | rpoB sequence-based phylogenetic tree of the isolates of NTM from water samples of hospitals with those of closely related species which computed by the NJ analyses and K2P model. The support of each branch, as determined from 1000 bootstrap samples, is indicated by percentages at each node. Bar 0.01 substitutions per nucleotide position.

by NTM (Mirsaeidi et al., 2014). Other reports from Iran, have demonstrated $M$. fortuitum as the dominant species both in water and clinical samples (Shojaei et al., 2011; Moghim et al., 2012; Nasr-Esfahani et al., 2012; Hashemi-Shahraki et al., 2013). In contrast, in several different studies, M. gordonae, M. kansasii, and M. chelonae were shown to be the most prevalent mycobacterial species in water supplies of hospitals (Sebakova et al., 2008; Shin et al., 2008; Hussein et al., 2009; Montanari et al., 2009).

In this study, several species of potential pathogenic NTM such as Mycobacterium simiae were also recovered. M. simiae pseudo-outbreaks had been reported by El Sahly et al. (2002), from a community teaching hospital in Houston, Texas. In their report, contaminated hospital water supply was identified as a source of human outbreak. Hashemi-Shahraki et al. (2013), have been reported M. simiae as emerging pathogen from Iran, with no person to person transmission. In such cases, water might be served as main source of human infection.

In current study, from 54 dental units, we recovered 22 NTM species including M. fortuitum, Mycobacterium colombiense, and M. gordonae. Schulze-Röbbecke et al. (1995), were reported the isolation of $M$. gordonae, M. flavescens, M. chelonae, $M$. chelonae-like organism, and $M$. simiae from dental units. This finding leaded to conclusion that, high numbers of NTM may be swallowed, inhaled or inoculated into oral wounds during dental treatment and in some case resulting in colonization, sensitization or infection. 
TABLE 3 | Frequency of NTM isolates from different hospital water sources.

\begin{tabular}{|c|c|c|c|}
\hline $\begin{array}{l}\text { Water } \\
\text { sources }\end{array}$ & $\begin{array}{l}\text { Number }(\%) \\
\text { of } \\
\text { samples }\end{array}$ & $\begin{array}{c}\text { Number (\%) } \\
\text { of positive } \\
\text { samples }\end{array}$ & $\begin{array}{l}\text { NTM species } \\
\text { (based on } \\
\text { analysis) }\end{array}$ \\
\hline $\begin{array}{l}\text { Hospital Tap } \\
\text { water }\end{array}$ & 135 & 26 & $\begin{array}{l}\text { M. fortuitum (12), M. gordonae } \\
\text { (6), M. phocaicum (3), } \\
\text { M. senegalense (2), } \\
\text { M. engbaekii (2), Unidentified (1) }\end{array}$ \\
\hline $\begin{array}{l}\text { Dentistry units } \\
\text { water }\end{array}$ & 54 & 22 & $\begin{array}{l}\text { M. fortuitum (13), M. gordonae } \\
\text { (2), M. iranicum (1), } \\
\text { M. colombiense (3), } \\
\text { M. lentiflavum (1), } \\
\text { M. novocasterense (1), } \\
\text { M. phocaicum (1) }\end{array}$ \\
\hline $\begin{array}{l}\text { Haemodialysis } \\
\text { center }\end{array}$ & 17 & 8 & $\begin{array}{l}\text { M. fortuitum (3), } \\
\text { M. novocastrense (2), } \\
\text { M. senegalense (2), } \\
\text { M. lentiflavum (1) }\end{array}$ \\
\hline $\begin{array}{l}\text { Ventilator } \\
\text { water }\end{array}$ & 25 & 7 & $\begin{array}{l}\text { M. simiae (3), M. colombiense } \\
\text { (2), M. fortuitum (2) }\end{array}$ \\
\hline Water tank & 27 & 14 & $\begin{array}{l}\text { M. fortuitum (4), M. gordonae } \\
\text { (5), M. senegalense (2), } \\
\text { M. lentiflavum (2), } \\
\text { Unidentified (1) }\end{array}$ \\
\hline
\end{tabular}

Dental unit waterline usually contaminated with the respiratory pathogens such as Legionella spp., Mycobacterium spp., and Pseudomonads. Nevertheless, in order to decrease infection risk, less than 200 colony-forming units (CFU) per $\mathrm{ml}$ of aerobic bacteria should be considered as a standard of the dental unit water (Pankhurst, 2003). Although, CFU of mycobacteria in dental units was not evaluated in our study, but recovery of potential pathogenic NTM from the dental water samples confirmed the high risk of NTM infection in individuals undergo dental procedures. Despite high aerosolization of NTM during dental treatment, a minimum rate of infection and sensitization risks associated with NTM, was reported (Dutil et al., 2007). Similar to our study, frequent isolation of NTM from dental units in different parts of the world.

(Schulze-Röbbecke et al., 1995; Pankhurst, 2003; Walker et al., 2004; Dutil et al., 2007), emphasizes the need for effective mechanisms to reduce NTM burden within dental unit systems, and highlights the risk of occupational exposure and infection in general dental practice.

A fairly diverse potential pathogenic NTM species was recovered in our study including $M$. colombiense, which is belong to the M. avium complex (MAC). This species is responsible for lymphadenopathy in immunocompetent children in Spain (Esparcia et al., 2008), and France (Vuorenmaa et al., 2009). In this study, we recovered this species form dental units and ventilator water samples. This is the first report for isolation of this species from Iran.

Falkinham (2010), reported high numbers of M. avium isolates from bronchoscopes and the filters used for washing them in USA. In their study, from water and biofilm samples collected from the bronchoscopies, M. avium, $M$. intracellulare, M. malmoense, and M. gordonae recovered, showing the contamination of bronchoscopes with water supply.

Our results showed high diverse patterns for 35\% (27 isolates) saprophytic mycobacteria and 50\% (50 isolates) potentially pathogenic mycobacteria. In compare, in a report from Korea, half of the tap water samples (50 of 100) from different parts of the hospital were positive for mycobacteria including saprophytic mycobacteria (73.3\%), potentially pathogenic mycobacteria (21.7\%) and unidentifiable strains 5\% (Shin et al., 2007).

In Turkey, Genc et al. (2013) examined 160 water samples from various departments of two hospitals in Istanbul. Based on their report, NTM were detected in 33 (20.6\%) samples, and $M$. lentiflavum, $M$. gordonae, and $M$. peregrinum, were the most common NTM isolated in rates of $60.6,30.3$, and 9.1\%, respectively. In concordant to their report, we demonstrated a rate of $29.8 \%$ NTM from water samples, however the NTM species diversity including RGM, was higher in our study compared to them.

Fernandez-Rendon et al. (2012), in Mexico City, reported potable water samples including cistern, kitchen tap, and bathroom showers harbored NTM species mostly Mycobacterium mucogenicum, while $M$. rhodesiae, $M$. peregrinum, and M. fortuitum were recovered as rare species. Several reports from other parts of the world (Walker et al., 2004; Hussein et al., 2009; Briancesco et al., 2014; Crago et al., 2014) showed that contamination of water resources in hospital, is not restricted to poor setting. Although, our setting as a poor one, showed high contamination rate and more diverse potential pathogenic species of NTM.

Contamination of hemodialysis fluid with whole cell of bacteria or their fragments is a significant health risk for hemodialysis patients (Glorieux et al., 2009). In our study, from 17 hemodialysis water samples, we recovered 8 NTM species including $M$. fortuitum $(n=3)$, M. novocastrense $(n=2)$, M. senegalense $(n=2)$, and M. lentiflavum $(n=$ 1). In line with our findings, high levels of contamination in dialysis water fluid were reported in different medical settings. At hemodialysis centers in nine hospitals in Japan, Oie et al. (2003), reported high contamination of dialysate. Of 40 dialysate samples analyzed, $42.5 \%$ showed a bacterial count of more than $2000 \mathrm{CFU} / \mathrm{ml}$, which was above the standard. In another similar study conducted in the Brazil, 11 mycobacterial species (M. gastri, M. kansasii, M. lentiflavum, and M. gordonae) were identified from 19 hemodialysis machines (Montanari et al., 2009). Moreover, in a recent study from Iran, from 80 samples originated from hemodialysis distribution system of the hospitals under investigation, a diverse bacterial community, including Mycobacteria, was detected (Heidarieh et al., 2016).

Due to the risk of NTM-contaminated hospital water supplies for nosocomial infections, preventive measures may be considered in hospitalized patients particularly whom suffering from immunosuppression conditions. Hospital potable water harboring saprophytic and potentially pathogenic NTM represents a potential source for nosocomial infections. 

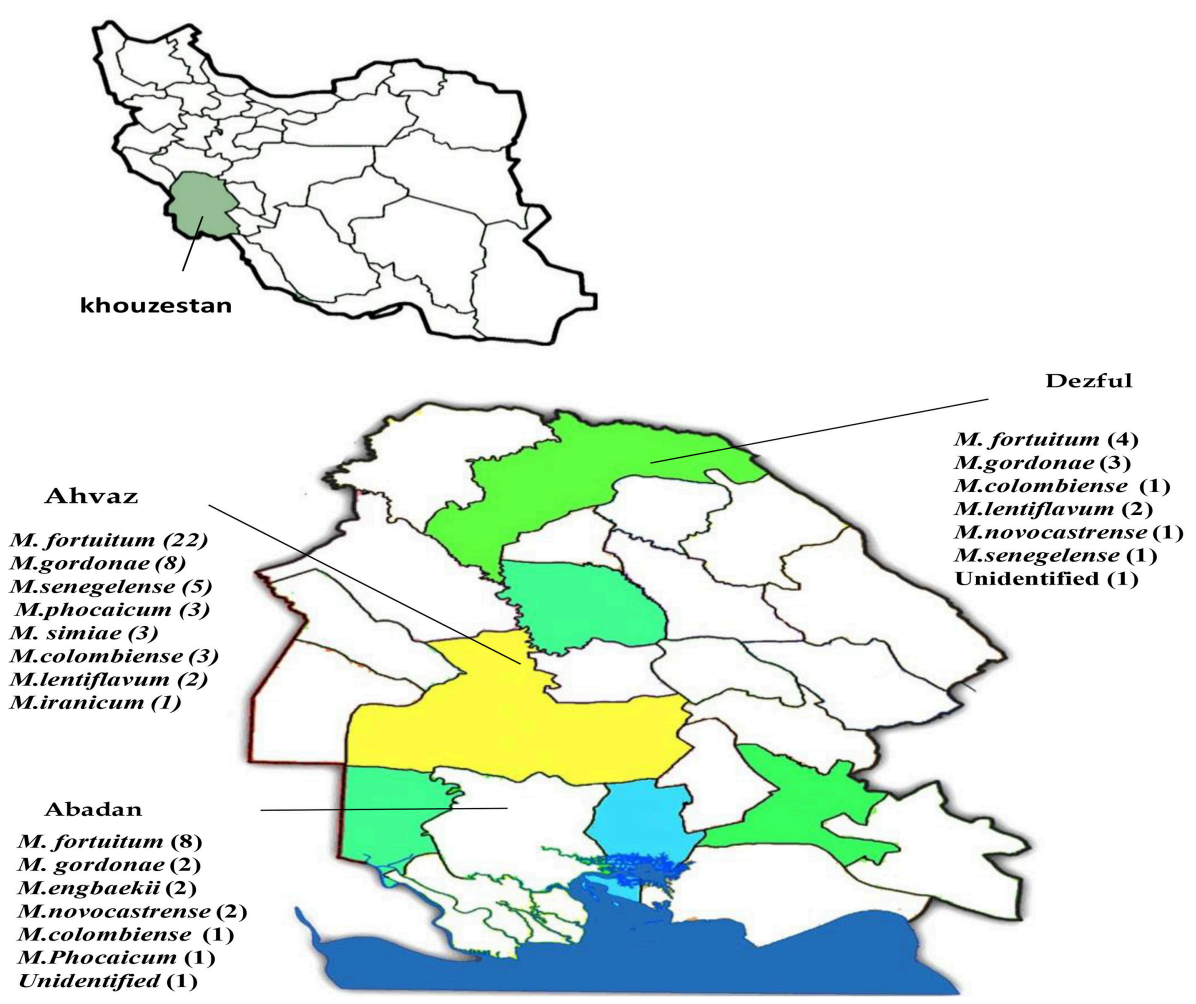

FIGURE 2 | Geographic distribution of NTM species among the hospitals of three area of Khuzestan.

In conclusion, the findings of the present study suggest that, water is an important environmental source harboring NTM. Furthermore, the wide presence of NTM in the aquatic sources throughout Khuzestan, Iran, is a potential public health hazard especially for those with immunodeficiency, calls for more effective water disinfection procedures in these units. A wide range of sources, exposures, and modes of transmission need to be investigated and additional studies are needed to correlate patient and environmental isolates. This is where the genetic identification using molecular techniques becomes useful since they can increase the specificity, sensitivity and the accuracy of the diagnosis.

\section{AUTHOR CONTRIBUTIONS}

AK: Substantial contributions to the conception or design of the work; Final approval of the version to be published; Agreement to be accountable for all aspects of the work in ensuring that questions related to the accuracy or integrity of any part of the work are appropriately investigated and resolved. AS: Substantial contributions to the conception or design of the

\section{REFERENCES}

Adékambi, T., Colson, P., and Drancourt, M. (2003). rpoB -based identification of nonpigmented and late-pigmenting rapidly growing mycobacteria. J. Clin. Microbiol. 41, 5699-5708. doi: 10.1128/JCM.41.12.5699-5708.2003 work; Final approval of the version to be published; Agreement to be accountable for all aspects of the work in ensuring that questions related to the accuracy or integrity of any part of the work are appropriately investigated and resolved. $\mathrm{MH}$ : Substantial contributions to the conception or design of the work; Drafting the work or revising it critically for important intellectual content; the acquisition, analysis, and interpretation of data for the work. RM: acquisition, analysis, interpretation of data for the work; Final approval of the version to be published. AT: acquisition, analysis, interpretation of data for the work; Agreement to be accountable for all aspects of the work in ensuring that questions related to the accuracy or integrity of any part of the work are appropriately investigated and resolved.

\section{ACKNOWLEDGMENTS}

This work was approved in Infectious and Tropical Diseases Research Center, and was financially supported by grants (No. TB-04 and TB-12) from Research affairs, Ahvaz Jundishapur University of Medical Sciences, Ahvaz, Iran.

Briancesco, R., Alaimo, C., Bonanni, E., Delle Site, A., Di Gianfilippo, F., Grassano, L., et al. (2014). An Italian investigation on non-tuberculous mycobacteria in an urban water supply. Ann. Ig. 26, 264-271. doi: 10.7416/ai.2014.1984

Castillo-Rodal, A. I., Mazari-Hiriart, M., Lloret-Sánchez, L. T., Sachman-Ruiz, B., Vinuesa, P., and López-Vidal, Y. (2012). Potentially pathogenic nontuberculous 
mycobacteria found in aquatic systems. Analysis from a reclaimed water and water distribution system in Mexico City. Eur. J. Clin. Microbiol. Infect. Dis. 31, 683-694. doi: 10.1007/s10096-011-1359-y,

CDC. (2003). Guidelines for Environmental Infection Control in Health-Care Facilities Recommendations: Water, and Environmental Sampling. Availble online at: http://www.cdc.gov/mmwr/PDF/rr/rr5210.pdf

Chimara, E., Ferrazoli, L., Ueky, S. Y., Martins, M. C., Durham, A. M., Arbeit, R. D., et al. (2008). Reliable identification of mycobacterial species by PCR-Restriction Enzyme Analysis (PRA)-hsp65 in a reference laboratory and elaboration of a sequence-based extended algorithm of PRA-hsp65 patterns. BMC Microbiol. 8:48. doi: 10.1186/1471-2180-8-48

Crago, B., Ferrato, C., Drews, S. J., Louie, T., Ceri, H., Turner, R. J., et al. (2014), Surveillance and molecular characterization of non-tuberculous mycobacteria in a hospital water distribution system over a three-year period. J. Hosp. Infect. 87, 59-62. doi: 10.1016/j.jhin.2014.03.002

Decker, B. K., and Palmore, T. N. (2013). The role of water in healthcareassociated infections. Curr. Opin. Infect. Dis. 26, 345-351. doi: 10.1097/QCO.0b013e3283630adf

Donohue, M. J., Mistry, J. H., Donohue, J. M., O’Connell, K., King, D., Byran, J., et al. (2015). Increased frequency of nontuberculous mycobacteria detection at potable water taps within the united states. Environ. Sci. Technol. 49, 6127-6133. doi: 10.1021/acs.est.5b00496

Dutil, S., Veillette, M., Mériaux, A., Lazure, L., Barbeau, J., and Duchaine, C. (2007). Aerosolization of mycobacteria and legionellae during dental treatment: low exposure despite dental unit contamination. Environ. Microbiol. 9, 2836-2843. doi: 10.1111/j.1462-2920.2007.01395.x

Edirisinghe, E. A., Dissanayake, D. R., Abayasekera, C. L., and Arulkanthan, A. (2014). Occurrence of nontuberculous mycobacteria in aquatic sources of Sri Lanka. Int. J. Mycobacteriol. 3, 242-246. doi: 10.1016/j.ijmyco.2014.10.007

El Sahly, H. M., Septimus, E., Soini, H., Septimus, J., Wallace, R. J., Pan, X., et al. (2002). Mycobacterium Simiae pseudo-outbreak resulting from a contaminated hospital water supply in Houston, Texas. Clin. Infect. Dis. 35, 802-807. doi: $10.1086 / 342331$

Esparcia, Ó., Navarro, F., Quer, M., and Coll, P. (2008). Lymphadenopathy caused by Mycobacterium colombiense. J. Clin. Microbiol. 46, 1885-1887. doi: 10.1128/JCM.01441-07

Falkinham, J. O. (2010). Hospital water filters as a source of Mycobacterium avium complex. J. Med. Microbiol. 59, 1198-1202. doi: 10.1099/jmm.0.022376-0

Falkinham, J. O. (2015). Environmental sources of nontuberculous mycobacteria. Clin. Chest Med. 36, 35-41. doi: 10.1016/j.ccm.2014.10.003

Fernandez-Rendon, E., Cerna-Cortes, J. F., Ramirez-Medina, M. A., HelgueraRepetto, A. C., Rivera-Gutierrez, S., Estrada-Garcia, T., et al. (2012). Mycobacterium Mucogenicum and other non-tuberculous mycobacteria in potable water of a trauma hospital: a potential source for human infection. J. Hosp. Infect. 80, 74-76. doi: 10.1016/j.jhin.2011.10.003

Genc, G. E., Richter, E., and Erturan, Z. (2013). Isolation of nontuberculous mycobacteria from hospital waters in Turkey. APMIS 121, 1192-1197. doi: 10.1111/apm.12066

Glorieux, G., Schepers, E., Schindler, R., Lemke, H. D., Verbeke, F., Dhondt, A., et al. (2009). A novel bio-assay increases the detection yield of microbiological impurity of dialysis fluid, in comparison to the LAL-test. Nephrol. Dial. Transplant. 24, 548-554. doi: 10.1093/ndt/gfn485

Hashemi-Shahraki, A., Zaker Bostanabad, S., Heidarieh, P., Titov, L. P., Khosravi, A. D., Sheikhi, N., et al. (2013). Species spectrum of nontuberculous mycobacteria isolated from suspected tuberculosis patients, identification by multi locus sequence analysis. Infect. Genet. Evol. 20, 312-324. doi: 10.1016/j.meegid.2013.08.027

Heidarieh, P., Shahraki, A. H., Yaghoubfar, R., Hajehasani, A., and Mirsaeidi, M. (2016). Microbiological analysis of hemodialysis water in a developing country. ASAIO J. doi: 10.1097/MAT.0000000000000353. [Epub ahead of print].

Hussein, Z., Landt, O., Wirths, B., and Wellinghausen, N. (2009). Detection of nontuberculous mycobacteria in hospital water by culture and molecular methods. Int. J. Med. Microbiol. 299, 281-290. doi: 10.1016/j.ijmm.2008.07.004

Iii, J. O. F. (2015). Environmental sources of nontuberculous mycobacteria. Clin. Chest Med. 36, 35-41. doi: 10.1016/j.ccm.2014.10.003

Jeon, Y. S., Chung, H., Park, S., Hur, I., Lee, J. H., and Chun, J. (2005). JPHYDIT: a java-based integrated environment for molecular phylogeny of ribosomal RNA sequences. Bioinformatics 21, 3171-3173. doi: 10.1093/bioinformatics/ bti463
Kent, P. T., and Kubica, G. P. (1985). Public Health Mycobacteriology: A Guide for the Level III Laboratory. Atlanta, GA: In Centers for Disease Control, U.S. Department of Health and Human Services.

Khosravi, A. D., Seghatoleslami, S., and Hashemzadeh, H. (2009). Application of PCR-Based fingerprinting for detection of nontuberculous mycobacteria among patients referred to tuberculosis reference center of Khuzestan province, Iran. Res. J. Microbiol. 4, 143-149. doi: 10.3923/jm.2009.143.149

Martin, A., Uwizeye, C., Fissette, K., De Rijk, P., Palomino, J. C., Leao, S., et al. (2007). Application of the hsp65 PRA method for the rapid identification of mycobacteria isolated from clinical samples in Belgium. J. Microbiol. Methods. 71, 39-43. doi: 10.1016/j.mimet.2007.07.008

Mirsaeidi, M., Farshidpour, M., Allen, M. B., Ebrahimi, G., and Falkinham, J. O. (2014). Highlight on advances in nontuberculous mycobacterial disease in North America. Biomed. Res. Int. 2014:919474. doi: 10.1155/2014/919474

Moghim, S., Sarikhani, E., Nasr Esfahani, B., and Faghri, J. (2012). Identification of nontuberculous mycobacteria species isolated from water samples using phenotypic and molecular methods and determination of their antibiotic resistance patterns by E- Test method, in Isfahan, Iran. Iranian J. Basic Med. Sci. 15, 1076-1082.

Montanari, L. B., Sartori, F. G., Cardoso, M. J., Varo, S. D., Pires, R. H., Leite, C. Q., et al. (2009). Microbiological contamination of a hemodialysis center water distribution system. Rev. Inst. Med. Trop. São Paulo 51, 37-43. doi: 10.1590/S003646652009000100007

Moore, J. E., Kruijshaar, M. E., Ormerod, L. P., Drobniewski, F., and Abubakar, I. (2010). Increasing reports of non-tuberculous mycobacteria in England, Wales and Northern Ireland, 1995-2006. BMC Public Health 10:612. doi: 10.1186/1471-2458-10-612

Narang, R., Narang, P., and Mendiratta, D. K. (2009). Isolation and identification of nontuberculous mycobacteria from water and soil in central India. Indian J. Med. Microbiol. 27, 247-250. doi: 10.4103/0255-0857.53208

Nasiri, M. J., Dabiri, H., Darban-Sarokhalil, D., and Hashemi Shahraki, A. (2015). Prevalence of non-tuberculosis mycobacterial infections among tuberculosis suspects in Iran: systematic review and meta-analysis. PLoS ONE. 10:e0129073. doi: 10.1371/journal.pone.0129073

Nasr-Esfahani, B., Sarikhani, E., Moghim, S., Faghri, J., Fazeli, H., Hoseini, N., et al. (2012). Molecular characterization of environmental non-tuberculous mycobacteria using PCR-RFLP analysis of 441 bp heat shock protein 65 fragments. Iran. J. Public Health 41, 108-114.

Neumann, M., Schulze-Robbecke, R., Hagenau, C., and Behringer, K. (1997). Comparison of methods for isolation of mycobacteria from water. Appl. Environ. Microbiol. 63, 547-552.

Oie, S., Kamiya, A., Yoneda, I., Uchiyama, K., Tsuchida, M., Takai, K., et al. (2003). Microbial contamination of dialysate and its prevention in haemodialysis units. J. Hosp. Infect. 54, 115-119. doi: 10.1016/S0195-6701(02)00402-4

Pankhurst, C. L. (2003). Risk assessment of dental unit waterline contamination. Prim. Dent. Care 10, 5-10. doi: 10.1308/135576103322504030

Parashar, D., Chauhan, D. S., Sharma, V. D., Chauhan, A., Chauhan, S. V., and Katoch, V. M. (2004). Optimization of procedures for isolation of mycobacteria from soil and water samples obtained in northern India. Appl. Environ. Microbiol. 70, 3751-3753. doi: 10.1128/AEM.70.6.3751-3753.2004

Peters, M., Müller, C., Rüsch-Gerdes, S., Seidel, C., Göbel, U., Pohle, H. D., et al. (1995). Isolation of atypical mycobacteria from tap water in hospitals and homes: is this a possible source of disseminated MAC infection in AIDS patients? J. Infect. 31, 39-44. doi: 10.1016/S0163-4453(95)91333-5

Schulze-Röbbecke, R., Feldmann, C., Fischeder, R., Janning, B., Exner, M., and Wahl, G. (1995). Dental units: an environmental study of sources of potentially pathogenic mycobacteria. Tuber. Lung Dis. 76, 318-323. doi: 10.1016/S09628479(05)80030-9

Sebakova, H., Kozisek, F., Mudra, R., Kaustova, J., Fiedorova, M., Hanslikova, D., et al. (2008). Incidence of nontuberculous mycobacteria in four hot water systems using various types of disinfection. Can. J. Microbiol. 54, 891-898. doi: 10.1139/W08-080

Shin, J. H., Lee, E. J., Lee, H. R., Ryu, S. M., Kim, H. R., Chang, C. L., et al. (2007). Prevalence of non-tuberculous mycobacteria in a hospital environment. J. Hosp. Infect. 65, 143-148. doi: 10.1016/j.jhin.2006.10.004

Shin, J. H., Lee, H. K., Cho, E. J., Yu, J. Y., and Kang, Y. H. (2008). Targeting the $r p o B$ gene using nested pcr-restriction fragment length polymorphism for identification of nontuberculous mycobacteria in hospital tap water. $J$. Microbiol. 46, 608-614. doi: 10.1007/s12275-008-0102-6 
Shojaei, H., Heidarieh, P., Hashemi, A., Feizabadi, M. M., and Daei Naser, A. (2011). Species identification of neglected nontuberculous mycobacteria in a developing country. Jpn. J. Infect. Dis. 64, 265-271.

Tamura, K., Dudley, J., Nei, M., and Kumar, S. (2007). MEGA4: molecular evolutionary genetics analysis (MEGA) software version 4.0. Mol. Biol. Evol. 24, 1596-1599. doi: 10.1093/molbev/msm092

Telenti, A., Marchesi, F., Balz, M., Bally, F., Böttger, E. C., and Bodmer, T. (1993). Rapid identification of mycobacteria to the species level by polymerase chain reaction and restriction enzyme analysis. J. Clin. Microbiol. 31, 175-178.

Vaerewijck, M. J., Huys, G., Palomino, J. C., Swings, J., and Portaels, F. (2005). Mycobacteria in drinking water distribution systems: ecology and significance for human health. FEMS Microbiol. Rev. 29, 911-934. doi: 10.1016/j.femsre.2005.02.001

Vuorenmaa, K., Salah, I. B., Barlogis, V., Chambost, H., and Drancourt, M. (2009). Mycobacterium colombiense and pseudotuberculous lymphadenopathy. Emerging Infect. Dis. 15, 618-620. doi: 10.3201/eid1504.081436
Walker, J. T., Bradshaw, D. J., Finney, M., Fulford, M. R., Frandsen, E., ØStergaard, E., et al. (2004). Microbiological evaluation of dental unit water systems in general dental practice in Europe. Eur. J. Oral Sci. 112, 412-418. doi: 10.1111/j.1600-0722.2004.00151.x

Conflict of Interest Statement: The authors declare that the research was conducted in the absence of any commercial or financial relationships that could be construed as a potential conflict of interest.

Copyright $\odot 2016$ Khosravi, Hashemi Shahraki, Hashemzadeh, Sheini Mehrabzadeh and Teimoori. This is an open-access article distributed under the terms of the Creative Commons Attribution License (CC BY). The use, distribution or reproduction in other forums is permitted, provided the original author(s) or licensor are credited and that the original publication in this journal is cited, in accordance with accepted academic practice. No use, distribution or reproduction is permitted which does not comply with these terms. 